\title{
POINT-COUNTERPOINT
}

\section{The argument for surgical therapy for stress urinary incontinence in females}

\author{
Richard Baverstock, MD, FRCSC; Kevin Carlson, MD, FRCSC
}

vesia [Alberta Bladder Centre], Division of Urology, University of Calgary, Calgary, AB

Cite as: Can Urol Assoc J 2012;6(1):59-61. http://dx.doi.org/10.5489/cuaj.12012

S tress urinary incontinence (SUI) affects $4 \%$ to $35 \%$ of women. ${ }^{1}$ Many patients find it difficult to bring up the topic of incontinence, so it is imperative that when the complaint is brought forward, we deal with it swiftly and in the most effective manner possible. In 2007, Harris and colleagues published that only $45 \%$ of women and $22 \%$ of men with incontinence disclosed it to a health care provider; of those, only $60 \%$ received treatment. Furthermore, half of those $60 \%$ felt that they continued to have daily leakage and remained frustrated. ${ }^{2}$ Surgery for SUI is fast and effective.

Once the SUI diagnosis has been made and other significant dysfunction has been ruled out, the patient and provider must agree on an initial therapeutic approach. Surgery should not be offered immediately to: (1) women of childbearing age who have not completed their family planning; (2) women with significant comorbidities and high surgical risk; and (3) women with overactive bladder $(\mathrm{OAB})$ and mixed urinary incontinence, where the $\mathrm{OAB}$ has not been first addressed. Notwithstanding these contraindications, surgery for SUI is often straightforward and the best option. All incontinence surgeons love the words, "Can't I just have surgery?"

Before we pour on the accolades for mid-urethral sling (MUS) surgery and declare it a winner (can you beat success rates of $77 \%$ cure rate at 11 years from Finland ${ }^{3}$ or the $85 \%$ cure rate at 7 years from Greece $^{4}$ ), we are obliged to look at the alternatives. We all attempt to modify our patient's behaviours, such as reduce their coffee intake, increase weight loss and suggest pelvic floor physiotherapy. Yet each surgeon wonders: "When will this fail and when can I book her surgery?" Behaviour modification is not successful because patients need to understand, learn about their condition, perform regular and intentional physical exercises and consciously make challenging lifestyle adjustments. Most people are incapable of taking on this responsibility or are unwilling to pay for uninsured services.

\section{Weight loss}

Let's examine weight loss, reported to be successful as a treatment for SUI. One trial in the New England Journal of Medicine looked at one female group of 226 patients who underwent an "intensive 6 month weight loss program that included diet, exercise and behaviour modification," and a control group of 112 female patients who entered a "structured education program." ${ }^{5}$ During the 6 months, the "intensive group" saw an $8 \%$ weight loss and a $47 \%$ reduction in incontinence episodes. The control group experienced a $1.6 \%$ weight loss and a $28 \%$ reduction in incontinence episodes. ${ }^{5}$ This is fantastic as long as when you suggest to a woman that she "lose weight to help her leakage" you can offer her a program that is this intensive and worthy of publication in the New England Journal of Medicine. In 2010, MacFarlane and Thomas summarized it best when they said ... "in practice it is inordinately difficult and only a small percentage manage to maintain their weight loss over the long term. ${ }^{\prime \prime}$ In another study, patients in an intensive lifestyle intervention lost $4.7 \%$ of their initial weight at 4 years, while only $1.1 \%$ in the diabetes support and education group lost weight. ${ }^{7}$ Losing weight is very difficult so relying on it as a treatment for $\mathrm{SUI}$ is almost useless.

\section{Pelvic floor muscle training}

Pelvic floor muscle training (PFMT), particularly under the direction of a dedicated pelvic floor physiotherapist or nurse continence advisor (NCA), can be successful about $40 \%$ of the time; however, at a considerable cost (time and money) to the patient. ${ }^{8}$ In Dumoulin and Hay-Smith's light reading 54-page Cochrane Review from 2010, they compare the results of PFMT to no treatment or inactive controls. They conclude that PFMT is better than no treatment. They felt PFMT should be offered as first-line treatment of SUI; however, they also conclude that there is no evidence that 
PFMT is cost-effective in the short- or long-term. ${ }^{9}$ In summary, PFMT is expensive to the patient ( $\$ 100$ to $\$ 175 / \mathrm{hr}$ ), invasive to a point, time-consuming, and best completed in a supervised setting; however, it may not be cost-effective in the long-term and the success outside of a structured setting is unknown. Sign us up!

\section{Medical therapy}

Is there a role for medical therapy for SUI? No. Duloxetine was never approved by the FDA or Health Canada for stress incontinence. Nausea rates of $23 \%$ and cure being similar to placebo stopped its progression. ${ }^{10}$ Recently, several large studies have put the nail in the coffin for oral and topical estrogen therapy as treatments for incontinence; these studies showed that these therapies worsened incontinence! $!^{11-13}$

\section{The case for surgery}

To this point, we've "poked holes" in the conservative treatments for SUI. We can now argue the benefits of SUI surgery and, especially in the modern era, the benefit of MUS, such as the tension-free vaginal tape (TFVT) devices and the trans-obturator tapes (TOT), which have quickly become the gold standard for surgical therapy of female SUI since its introduction in 1993. ${ }^{14}$ Their high surgical cure rates $(70 \%$ to $99 \%)$, minimally invasive nature, short length of stay and tolerable complication profile have established this reputation. ${ }^{15}$ In our randomized comparative trial of TFVT versus TOT, at 12 months we witnessed a $77 \%$ and $81 \%$ cure rate as defined rigorously as $<1 \mathrm{~g}$ of urine on defined pad test. ${ }^{16}$ Others have reported similar cure rates, albeit with varying definitions of cure. Recently, Esin and colleagues reported excellent success with the TOT even in obese patients, with cure rates of $92 \%$ and $91.3 \%$ for obese and non-obese patients, respectively. ${ }^{17}$ Additionally, complication rates were low and similar in both groups. Critics may argue that these trials suffer from short follow-up; however, the Finnish study shows the durability of surgical therapy for SUI. ${ }^{3}$ In this study, $77 \%$ of the initial 90 women were available for follow-up at 11.5 years post-TFVT, with $90 \%$ having a negative stress test and negative pad test. Subjectively, only $3 \%$ regarded their operation as a failure, while $77 \%$ were cured and $20 \%$ improved. Furthermore, no late complications, such as tape erosion, were seen. If $77 \%$ of our patients still considered themselves cured at 11 years, we would be delighted.

Having established the high success rate and the durability of the MUS, we must examine its safety. In the right hands, the MUS are not too risky. Published complication rates of MUS include $4.7 \%$ bladder perforation, $6 \%$ de novo $\mathrm{OAB}$ and $4 \%$ to $10 \%$ new onset urinary retention. ${ }^{15}$ In our TFVT versus TOT study, bladder perforation was $2.9 \%$ show- ing that experienced surgeons can have lower complication rates (though they still occur). Surgeons using mesh should be aware of the advisories from the US Food and Drug Administration ${ }^{18}$ and Health Canada ${ }^{19}$ and respect the materials they are working with. Additionally, surgeons performing MUS should advise patients that on occasion a secondary procedure for recurrent stress incontinence, urinary retention, refractory $\mathrm{OAB}$ or mesh erosion or extrusion may be necessary. Importantly, surgery for SUI should be performed by specialists with an acceptable volume of cases and who can effectively recognize and treat potential complications.

\section{Conclusion}

We have outlined the limitations of conservative treatments and highlighted the enormous success rates of surgical therapy with MUS, such as the TFVT and TOT. Ultimately, the choice will be with the patient, and many will select the fastest and most effective method to treat their stress incontinence, which is surgery.

Competing interests: Dr. Baverstock and Dr. Carlson are founders and directors of vesia [Alberta Bladder Centre].

This paper has been peer-reviewed.

\section{References}

1. Luber KM. The definition, prevalence, and risk factors for stress urinary incontinence. Rev Urol 2004;6(Suppl 3):S3-9.

2. Harris SS, Link CL, Tennstedt SL, et al. Care seeking and treatment for urinary incontinence in a diverse population. J Urol 2007;177:680-4. http://dx.doi.org/10.1016/i.juro.2006.09.045

3. Nilsson CG, Palva K, Rezapour $M$, et al. Eleven years prospective follow-up of the tension-free vaginal tape procedure for treatment of stress urinary incontinence. Int Urogynecol J Pelvic Floor Dysfunct 2008;19:1043-7. http://dx.doi.org/10.1007/s00192-008-0666-z

4. Liapis $A$, Bakas $P$, Creatsas $G$. Long-term efficacy of tension-free vaginal tape in the management of stress urinary incontinence in women: efficacy at 5-and 7-year follow-up. Int Urogynecol J Pelvic Floor Dysfunct 2008;19:1509-12. htrp://dx.doi.org/10.1007/s00192-008-0664-1

5. Subak LL, Wing R, West DS, et al. Weight loss to treat urinary incontinence in overweight and obese women. N Engl J Med 2009;360:481-90. http://dx.doi.org/10.1056/NEJMoa0806375

6. Macfarlane DJ, Thomas GN. Exercise and diet in weight management: updating what works. Br I Sports Med 2010;44:1197-201. Epub 2009 0ct 20. http://dx.doi.org/10.1136/bjsm.2009.065235

7. Wadden TA, Neiberg RH, Wing RR, et al. Four Year Weight Losses in the Look AHEAD Study: Factors Associated with Long-Term Success. Obesity (Silver Spring) 2011;19:1987-8. http://dx.doi. org/10.1038/oby.2011.230

8. Shamliyan TA, Kane RL, Wyman J, et al. Systematic review: randomized, controlled trials of nonsurgical treatments for urinary incontinence in women. Ann Intern Med 2008; 148:459-73.

9. Dumoulin C, Hay-Smith J. Pelvic floor muscle training versus no treatment, or inactive control treatments, for urinary incontinence in women. Cochrane Database Syst Rev 2010;1:CD005654. http://dx.doi. org/10.1002/14651858.CD005654.pub2

10. Millard RJ, Moore K, Rencken R, et al. Duloxetine UI Study Group Duloxetine vs placebo in the treatment of stress urinary incontinence: a four-continent randomized clinical trial. BJU Int 2004;93:311-8. http:// dx.doi.org/10.1111/i.1464-410X.2004.04607.x

11. Grady D, Brown JS, Vittinghoff E, et al. Postmenopausal hormones and incontinence: the Heart and Estrogen/Progestin Replacement Study. Obstet Gynecol 2001;97:116-20. http://dx.doi.org/10.1016/ 
S0029-7844(00)01115-7

12. Hendrix SL, Cochrane BB, Nygaard IE, et al. Effects of estrogen with and without progestin on urinary incontinence. JAMA 2005;293:935-48. http://dx.doi.org/10.1001/jama.293.8.935

13. Cody JD, Richardson K, Moehrer B, et al. Oestrogen therapy for urinary incontinence in post-menopausal women. Cochrane Database Syst Rev 2009;4:CD001405.

14. Ulmsten $\mathrm{U}$, Henriksson $\mathrm{L}$, Johnson $\mathrm{P}$, et al. An ambulatory surgical procedure under local anesthesia for treatment offemale urinary incontinence. Int Urogynecol J Pelvic Floor Dysfunct 1996;7:81-5. http:// dx.doi.org/10.1007/BF01902378

15. Ogah J, Cody JD, Rogerson L. Minimally invasive synthetic suburethral sling operations for stress urinary incontinence in women. Cochrane Database Syst Rev 2009;4:CD006375.

16. Ross $S$, Robert $M$, Swaby $C$, et al. Transobturator tape compared with tension-free vaginal tape for stress incontinence: a randomized controlled trial. Obstet Gynecol 2009;114:1287-94. http://dx.doi. org/10.1097/A0G.0b013e3181c2a151
17. Esin S, Salman MC, Ozyuncu 0 , et al. Surgical outcome of transobturator tape procedure in obese and non-obese women. J Obstet Gynaecol 2011;31:645-9. http://dx.doi.org/10.3109/01443615.20 11.597461

18. US Food and Drug Administration. FDA Safety Communication: UPDATE on Serious Complications Associated with Transvaginal Placement of Surgical Mesh for Pelvic Organ Prolapse. July 13, 2011. http://www.fda. gov/medicaldevices/safety/alertsandnotices/ucm262435.htm (Accessed February 6, 2012).

19. Health Canada. Surgical Mesh - Complications Associated with Transvaginal Implantation of Surgical Mesh for the Treatment of Stress Urinary Incontinence and Pelvic Organ Prolapse - Notice to Hospitals. February 4, 2012. httpp://www.hc-sc.gc.ca/dhp-mps/medeff/advisories-avis/prof/_2010/surgical-mesh_nthaah-eng.php (Accessed February 6, 2012)

Correspondence: Dr. Richard Baverstock, 6601, 7007 14th Street SW, Calgary, AB T2V 1P9; fax: 403-943-8979; drbaverstock@vesia.com

\title{
POINT-COUNTERPOINT
}

\section{Conservative treatment for female stress urinary incontinence: simple, reasonable and safe}

\author{
Boris Friedman, $M D$ \\ Department of Urologic Sciences, Bladder Care Center, University of British Columbia, Vancouver, BC
}

Cite as: Can Urol Assoc J 2012;6(1):61-3. http://dx.doi.org/10.5489/cuaj.12021

S tress urinary incontinence (SUI) is common among women and has a significant negative impact on daily functioning and quality of life. SUI also has a large economic impact on health systems necessitating the implementation of simple and cost-effective management plans. ${ }^{1}$ Although surgical treatments are widely used for SUI, many women prefer a self-managed conservative option to avoid long-term recurrence or possible devastating complications of surgical interventions. Moreover, some women are not eligible for surgery or prefer to defer it (i.e., women who plan to conceive). Pelvic floor muscle training (PFMT), vaginal devices, electrical stimulation and pharmacological agents (duloxetine) are conservative options for SUI.

\section{Pelvic floor muscle training}

Urethral closure is maintained by an adequate support provided by the endopelvic fascia and the tonic contraction of the levator ani muscles. When properly carried out, PFMT restores the ability to contract these muscles in a timed and coordinated way and thus improves or restores continence. $^{2}$ A systematic review of 12 trials (involving 672 women) showed better continence-specific quality of life, fewer incontinence episodes per day and less leakage on pad test in women who practiced PFMT compared to controls. ${ }^{3}$ A diligent physiotherapist and a motivated patient are needed to obtain good results with PFMT. PFMT could be taught in individual or in group sessions. Both methods yield similar improvement in clinical variables and in patient satisfaction. ${ }^{4} \mathrm{~A}$ recently published Cochrane review which compared several PFMT approaches for SUI found 
that regular supervision (e.g., weekly) combined with group sessions contribute to the success of PFMT; up to $90 \%$ of women reported improvement. ${ }^{5}$

Few studies reported the long-term results of PFMT. Bo and Talseth examined 23 women, 5 years after ceasing organized PFMT and found satisfaction rate of $70 \%$. Seventy percent of women were exercising the pelvic floor muscles at least once a week, $75 \%$ showed no leakage during stress test and mean pelvic floor muscle strength was maintained. ${ }^{6}$ Cammu et al showed that when PFMT is initially successful there is a $66 \%$ chance that the favourable result will persist for at least ten years. ${ }^{7}$ A recent review of long term outcomes of PMFT supports these finding, ${ }^{8}$ although other studies found lower success rates of PFMT. ${ }^{9}$ PFMT is non-invasive with negligible side effects and low costs and should be suggested as a first line choice in SUI management. ${ }^{10}$

\section{Weighted vaginal cones}

About $30 \%$ of women are unable to perform adequate voluntary muscle contractions. ${ }^{11}$ Vaginal cones produce an involuntary contraction of pelvic floor musculature in reaction to the cone weight in the vagina, thus strengthening and synchronizing PFM and reducing SUI. ${ }^{12,13}$ Cones are usually easy to insert, may be self-taught and used without supervision or vaginal examination. Women are instructed to insert the heaviest cone they can retain while standing and moving around; they can gradually increase cone weight as their muscle strength improves. Generally, the instructions are to carry the cone for two sessions of 15 minutes per day for one month or more, ${ }^{12}$ but the duration of therapy is controversial. The effectiveness of vaginal cones is similar to that of PFMT. ${ }^{12,14}$ Peattie and colleagues evaluated 30 patients who used vaginal cones, $70 \%$ of them were found to be completely dry or to have improved with respect to urinary loss after one month of treatment. ${ }^{15}$ Side effects, such as vaginal pain and increased vaginal discharge, were reported in one study among $10 \%$ of the patients, although no treatment was required and there was no need to discontinue therapy. ${ }^{16} \mathrm{~A}$ systematic review of 17 studies (involving 1484 women) on vaginal cone use for SUI treatment concluded that weighted vaginal cones are better than no active treatment and with similar effectiveness to PFMT. However, it pointed out that the drop-out rate in these studies was relatively high (average $25 \%$ ), suggesting that this modality is not always well-accepted among patients. ${ }^{12}$

\section{Biofeedback}

Both vaginal and anal surface electromyograms and urethral and vaginal squeeze pressure measurements have been used to make the patient more aware of muscle function and to enhance patient effort during PFMT. ${ }^{17}$ Biofeedback is not a treatment on its own, but an adjunct to training, measuring response while the patient is contracting. Several randomized controlled trials and systematic reviews, which compared PFMT with and without biofeedback, did not find significant benefit in adding biofeedback to PFMT. ${ }^{18,19} \mathrm{~A}$ recent Cochrane systematic review, which included 24 trials involving 1584 women with urinary incontinence, evaluated the effectiveness of adding biofeedback to PFMT. Women who received biofeedback were significantly more likely to report that their urinary incontinence was cured or improved compared to those who received PFMT alone (risk ratio 0.75, $95 \%$ confidence interval 0.66 to 0.86 ). However, it was not clear whether this was the effect of the biofeedback device itself or the benefit from spending more time in clinic with the doctor, nurse or physiotherapist. ${ }^{20}$

\section{Electrical stimulation}

Electrical stimulation either vaginal or extracorporeal is a modality which has been in clinical use in Europe and North America for three decades. Several early uncontrolled trials reported efficacy in urinary incontinence treatment, with improvement rates from $35 \%$ to $70 \%,{ }^{21,22}$ whereas in controlled trials the results were conflicting ${ }^{14,23}$ and no additional benefit over PFMT was demonstrated. ${ }^{24,25}$ The lack of evidence is compounded by differences in stimulation parameters and duration of treatment. Women with SUI who are having difficulties to correctly perform PFMT may benefit from a device which directly stimulates contraction of the pelvic floor.

\section{Incontinence pessary}

Incontinence pessary is intravaginal device with a knob that sits under the urethra to increase urethral support. It is an effective, self-managed option for SUI which is often underused due to a lack of knowledge regarding pessary fitting and its use in SUI. ${ }^{26,27}$ A major limitation is the difficulty in inserting it properly and correctly positioning the device. ${ }^{27}$ Nevertheless, more than half of the women who were successfully fitted with a pessary for SUI used it for the next 1 to 2 years. ${ }^{28} \mathrm{~A}$ newly designed tampon-shaped device is available in different sizes. A recent pilot study found it to be effective and easy to manipulate, with a $76 \%$ satisfaction rate after one year of usage. ${ }^{27}$

\section{Pharmacological treatment}

Different pharmacological agents, such as alpha adrenergic agonists, antidepressants and hormone replacement therapies, are not advocated for SUI due to the lack of significant benefit and high adverse effect profile. ${ }^{29}$ Duloxetine is a selective serotonin and norepinephrine reuptake inhibitor. 
Serotonin and norepinephrine promote urine storage by relaxing the bladder and increasing sphincter resistance..$^{30}$ Three large multicentre, double-blind, placebo-controlled trials investigated the efficacy of duloxetine to treat SUI. More than 1635 women in five different continents were included in these trials. The trials demonstrated that duloxetine can decrease the frequency of incontinence episodes by up to $50 \%$ compared to placebo. However, the high rate of treatment discontinuation (up to $22 \%$ ) due to adverse effects was consistent in all three trials; nausea was the most common adverse effect. ${ }^{30}$ Duloxetine was approved by the European Union to treat SUI in 2004. Despite its demonstrated efficacy, the manufacturer decided to market duloxetine for depression rather than SUI and presently does not sell it in the dose shown to be effective for SUI $(40 \mathrm{mg}$ twice daily). Clinical studies done after the approval had conflicting results suggesting that more studies are required to evaluate the utility of duloxetine in SUI treatment.

\section{Conclusion}

Conservative treatments for SUI are demonstrated to be beneficial, cost-effective and to have minimal side effects. Conservative management enables patients to be actively involved in the management of their SUI, while temporarily or permanently avoiding invasive procedures. According to current guidelines, lifestyle modifications (such as weight reduction) and conservative treatments should be advocated to all women with SUI as first-line treatment. ${ }^{10}$

Competing interests: None declared.

This paper has been peer-reviewed.

\section{References}

1. Wagner TH, Hu TW. Economic costs of urinary incontinence in 1995. Urology Dysfunct 1998;51:355-61

2. Wall L, Davidson TG. The role of muscular re-eduction by physical therapy in the treatment of genuine stress urinary incontinence. Obstet Gynecol Surv 1992;47:322-31. http://dx.doi.org/10.1097/00006254199205000-00015

3. Dumoulin C, Hay-Smith J. Pelvic floor muscle training versus no treatment, or inactive control treatments, for urinary incontinence in women. Cochrane Database Syst Rev 2010;1:CD005654. http://dx.doi. org/10.1002/14651858.CD005654.pub2

4. Pereira VS, Correia GN, Driusso P. Individual and group pelvic floor muscle training versus no treatment in female stress urinary incontinence: A randomized controlled pilot study. Eur I Obstet Gynecol Reprod Biol 2011;159:465-71. http://dx.doi.org/10.1016/i.ejogrb.2011.09.003

5. Hay-Smith EJC, Herderschee R, Dumoulin C, et al. Comparisons of approaches to pelvic floor muscle training for urinary incontinence in women. Cochrane Database Syst Rev 2011;12:CD009508. http:// dx.doi.org/10.1002/14651858.CD009508

6. Bo K, Talseth $\mathrm{T}$. Long-term effect of pelvic floor muscle exercise 5 years after cessation of organized training. Obstet Gynecol 1996;87:261-5. http://dx.doi.org/10.1016/0029-7844(95)60375-1

7. Cammu H, Van Nylen M, Amy JJ. A 10-year follow-up after Kegel pelvic floor muscle exercises for genuine stress incontinence. BJU International 2000;85:655-8. http://dx.doi.org/10.1046/i.1464410x.2000.00506.x
8. Davila GW. Nonsurgical outpatient therapies for the management of female stress urinary incontinence: Long-term effectiveness and durability. Adv Urol 2011;176498.

9. Hahn I, Milson I, Fall M, et al. Long-term results of pelvic floor training in female stress urinary incontinence. Br J Urol 1993;72:421-7. http://dx.doi.org/10.1111/i.1464-410X.1993.tb16170.x

10. Thuroff JA, Abrams P, Andersson KE, et al. EUA guidelines on urinary incontinence. Eur Urol 2011;59:387400. http://dx.doi.org/10.1016/i.eururo.2010.11.021

11. Bo K. Pelvic floor muscle strength and response to pelvic floor muscle training for stress urinary incontinence. Neurourol Urodyn 2003;22:654-8. http://dx.doi.org/10.1002/nau.10153

12. Herbison GP, Dean N. Weighted vaginal cones for urinary incontinence. Cochrane Database Syst Rev 2007;2:CD002114. http://dx.doi.org/10.1002/14651858.CD002114

13. Deindl FM, Schussler B, Vodusek DB, et al. Neurophysiologic effect of vaginal cone application in continent and urinary stress incontinent women. Int Urogynecol J Pelvic Floor Dysfunct 1995;6:204-8. http:// dx.doi.org/10.1007/BF01894264

14. Castro RA, Arruda RM, Zanetti MRD, et al. Single-blind, randomized, controlled trial of pelvic floor muscle training, electrical stimulation, vaginal cones, and no active treatment in the management of stress urinary incontinence. Clinics 2008;64:465-72. http://dx.doi.org/10.1590/S1807-59322008000400009

15. Peattie $A B$, Plevnik $S$, Stanton SL. Vaginal cones: a conservative method of treating genuine stress incontinence. Br J Obstet Gynaecol 1988;95:1049-53.http://dx.doi.org/10.1111/i.1471-0528.1988. tb06512.x

16. Kondo A, Yamada Y, Niijima R. Treatment of stress incontinence by vaginal cones: short- and long-term results and predictive parameters. Br J Urol 1995;76:464-6.http://dx.doi.org/10.1111/i.1464410X.1995.tb07746.x

17. Burgio KL, Robinson JC, Engel BT. The role of biofeedback in Kegel exercise training for stress urinary incontinence. Am J Obstet Gynecol 1986; 154:58-64.

18. Berghmans $L C$, Frederiks $C M$, de Bie RA, et al. Efficacy of biofeedback, when included with pelvic floor muscle exercise treatment, for genuine stress incontinence. Neurourol Urodyn 1996;15:37-52. http:// dx.doi.org/10.1002/(SICI) 1520-6777(1996) 15:1<37::AID-NAU4>3.0.C0;2-G

19. Mørkved S, Bo K, Fiørtoff T. Effect of adding biofeedback to pelvic floor muscle training to treat urodynamic stress incontinence. Obstet Gynecol 2002;100:730-39.http://dx.doi.org/10.1016/S00297844(02)02160-9

20. Herderschee R, Hay-Smith EJ, Herbison GP, et al. Feedback or biofeedback to augment pelvic floor muscle training for urinary incontinence in women. Cochrane Database Syst Rev 2011;7:CD009252. http:// dx.doi.org/10.1002/14651858.CD009252

21. Caputo RM, Benson JT, McClellan E. Intravaginal maximal electrical simulation in the treatment of urinary incontinence. J Reprod Med 1993;38:667-71.

22. Brubaker L, Benson JT, Bent $A$, et al. Transvaginal electrical stimulation for female urinary incontinence. Am J Obstet Gynecol 1997;177:536-40.http://dx.doi.org/10.1016/S0002-9378(97)70142-X

23. Knight $S$, Laycock J, Naylor D. Evaluation of neuromuscular electrical stimulation in the treatment of genuine stress incontinence. Physiotherapy 1998:84:61-71.http://dx.doi.org/10.1016/S0031$9406(05) 66541-8$

24. Luber KM, Wolde-Tsadik $G$. Efficacy of functional electrical stimulation in treating genuine stress incontinence: A randomised clinical trial. Neurourol Urodyn 1997;16:543-51. http://dx.doi.org/10.1002/ (SICI) 1520-6777(1997) 16:6<543::AID-NAU4>3.0.C0;2-E

25. Gilling PJ, Wilson LC, Westenberg AM, et al. A double-blind randomized controlled trial of electromagnetic stimulation of the pelvic floor vs sham therapy in the treatment of women with stress urinary incontinence. BJU Int 2009;103:1386-90.http://dx.doi.org/10.1111/i.1464-410X.2008.08329.x

26. Farrell $S A$, Singh $B$, Aldakhil L. Continence pessaries in the management of urinary incontinence in women. J Obstet Gynaecol Can 2004;26:113-7.

27. Farrell $S A$, Baydock $S$, Amir $B$, et al. Effectiveness of a new self-positioning pessary for the management of urinary incontinence in women. Am J Obstet Gynecol 2007:196:474.el-8.

28. Clemons JL, Aguilar VC, Sokol ER, et al. Patient characteristics that are associated with continued pessary use versus surgery after 1 year. Am J Obstet Gynecol 2004;191:159-64. http://dx.doi.org/10.1016/i.ajog.2004.04.048

29. Rogers RG. Urinary Stress Incontinence in Women. N Engl J Med 2008;358:1029-36. http://dx.doi.org/10.1056/NEJMcp0707023

30. Mariappan P, Alhasso A, Ballantyne Z, et al. Duloxetine, a Serotonin and Noradrenaline Reuptake Inhibitor (SNRI) for the Treatment of Stress Urinary Incontinence: A Systematic Review. Eur Urol 2007;51:67-74. http://dx.doi.org/10.1016/i.eururo.2006.08.041

Correspondence: Dr. Boris Friedman, Department of Urologic Sciences, Faculty of Medicine, The University of British Columbia, Gordon \& Leslie Diamond Health Care Centre Level 6, 2775 Laurel St., Vancouver, BC V5Z 1M9; fax: 604-875-4637; boris.friedman@vch.ca 